\title{
Analysis of Compounds Isolated from Gnetum gnemon L. Seeds as Potential ACE Inhibitors through Molecular Docking and Molecular Dynamics Simulations
}

\author{
Muhammad Aranza Triputra, Arry Yanuar* \\ Faculty of Pharmacy, Universitas Indonesia, Depok, 16424, INDONESIA.
}

\begin{abstract}
Objective: Gnetum gnemon L. (melinjo) seed extracts have been known to have some biological activities. One of them is ACE (angiotensinconverting enzyme) inhibitor. The present study was conducted to predict potential ACE inhibitory activity of several compounds isolated from Gnetum gnemon L. seeds by using in silico method. Methods: In this study, several compounds isolated from melinjo seeds were determined for their ACE inhibitory activity through molecular docking study and molecular dynamics simulations. Molecular docking experiment was performed by using AutoDock4Zn. Subsequently, molecular dynamics simulations using AMBER within $20 \mathrm{~ns}$ was conducted to analyze the interactions stability between zinc-ligand and ligand-amino acids in the active site of ACE since both of these mechanisms were known to play essential roles to inhibit ACE. Results: The results showed that resveratrol, gnetol, isorhapontigenin, gnetin $\mathrm{C}$, trans- $\varepsilon-$ viniferin, gnemonol $\mathrm{K}$, gnemonol $\mathrm{M}$ and aglycone of gnemonoside $B$ exhibited $\Delta G$ values which were lower than or close to lisinopril, captopril, and enalaprilat. Some of these ligands were able to bind zinc ion via cation-pi interactions. According to the free-energy binding calculations using MM-GBSA and MM-PBSA methods, gnetin C showed
\end{abstract}

the highest affinity for ACE among other ligands at a temperature of $300 \mathrm{~K}$, while at a temperature of $310 \mathrm{~K}$ the highest affinity was exhibited by gnemonol K. Conclusion: According to the molecular docking and molecular dynamics simulations, several compounds isolated from melinjo seed showed potential ACE inhibitory activities, in which gnemonol K promised as the most potential compound to have ACE inhibitory activity.

Key words: ACE, Cation-pi, Hypertension, Molecular docking, Molecular dynamics, Zinc ion.

\section{Correspondence}

Arry Yanuar, Faculty of Pharmacy, Universitas Indonesia, Depok, 16424, INDONESIA

Phone:+62-21-7270031

Email: arry.yanuar@ui.ac.id

DOI: 10.5530/jyp.2018.2s.7

\section{INTRODUCTION}

Indonesia has the opportunity to develop medicines or herbs that are essential for health. One of the plants having medicinal properties is Gnetum gnemon L. (melinjo). Melinjo is widely available and consumed in large quantities in Indonesia. ${ }^{1}$ Hydrolyzed-proteins of melinjo seed had been proven to lower blood pressure of hypertensive rats. ${ }^{2}$

Hypertension is a condition in which arterial blood pressure is continuously elevated. To be diagnosed with hypertension when one's systolic pressure is higher than $140 \mathrm{~mm} \mathrm{Hg}$, and the diastolic pressure reaches greater than or equal to $90 \mathrm{~mm} \mathrm{Hg} .{ }^{3}$ Hypertension affects about $40 \%$ of people aged 25 years or older, both in developing countries, and developed countries. ${ }^{4}$ Hypertension is a leading problem in Indonesia, because of the high prevalence and the long term effect. ${ }^{5}$ In 2013, Indonesia has $25.8 \%$ prevalence of adult over 18 years with hypertension based on blood pressure measurements using the sphygmomanometer. ${ }^{6}$ The majority of hypertensive patients rely on ACE (angiotensin-converting enzyme) inhibitors in managing their conditions. ${ }^{7}$ Angiotensin-converting enzyme (ACE) plays an inportant role in the conversion of angiotensin I to angiotensin II, a known potent vasoconstrictor. ${ }^{8}$ Furthermore, angiotensin II increases blood pressure which is the significant risk factor for hypertension. ${ }^{3}$

Gnetum gnemon L. (melinjo) is a plant that spreads in Southeast Asia, Melanesia, and the Pacific Islands. This tree has a height of 10-15 meters, with a slender-shaped trunk with a diameter of approximately
$40 \mathrm{~cm}$. This plant has one oval-shaped seed on each fruit. ${ }^{9}$ Melinjo belongs to Gnetum (Gnetaceae) genus plant, which is known containing many stilbene derivatives. ${ }^{10-12}$

Gnetum gnemon L. seed extracts have been known to have some biological activities. ${ }^{13}$ The previous research showed that the ethyl acetate extract of melinjo seed had the highest inhibitory activity towards ACE compared to other extraction solvents in vivo. ${ }^{14}$ Furthermore, there are compounds found in the ethyl acetate extract of melinjo seed such as resveratrol, gnetol, isorhapontigenin, trans-piceid, gnetin $\mathrm{C}$, trans- $\varepsilon$-viniferin, gnemonol $\mathrm{M}$, gnemonol $\mathrm{K}$, gnemonoside $\mathrm{A}$, gnemonoside $\mathrm{B}$, gnemonoside $\mathrm{C}$, gnemonoside $\mathrm{D}$, and latifolol. A recent research demonstrated that several compounds of melinjo seed extracts have a better affinity than lisinopril to ACE based on molecular docking results using AutoDock Vina. ${ }^{15}$ Therefore, this study conducted a further analysis of the ligand binding to amino acid residues at ACE active sites and the ligand binding to $\mathrm{Zn}^{2+}$ ions, which both of these mechanisms are important in ACE inhibition. ${ }^{16}$ These two essential interactions were analyzed through molecular docking using AutoDock4Zn, which generates more accurate free energy binding calculations than AutoDock Vina on ligand-Zn interactions. ${ }^{17}$ Molecular dynamics simulations were also conducted, involving several compounds in melinjo seed within $20 \mathrm{~ns}$ to check the stability of the ligand-enzyme complexes. ${ }^{18}$ 


\section{MATERIALS AND METHODS}

\section{Materials \\ Hardware}

A single computer with the Linux operating system Ubuntu 12.04 LTS was used to conduct molecular docking and molecular dynamics simulations. Following specifications are used: Intel ${ }^{\circledR} \mathrm{Xeon}^{\mathrm{E} 5620}$ (Intel $^{\circ}$ Core $^{\mathrm{rx}}$, American) processor (CPU) processors, Nvidia ${ }^{\oplus}$ GeForce GTX 780 (Nvidia, American) graphics processing unit (GPU) and 32 gigabytes (GB) Random Access Memory (RAM) DDR3.

\section{Software}

AutoDock4Zn forcefield was used to carry out the molecular docking, while AMBER PMEMD and VMD were used to conduct molecular dynamics simulations. LigandScout 4.09.2 and PoseView were also used to visualize the ligand-ACE binding from molecular docking and molecular dynamics simulations results.

\section{Three-dimensional structure of ACE}

The three-dimensional structure of ACE was obtained from the Research Collaboratory for Structural Bioinformatics Protein Data Bank (RCSB PDB) with identity (ID) 1O86. This protein is a testicular form of ACE (tACE) that contains $\mathrm{C}$ domain in the complex with lisinopril. Moreover, the macromolecule was optimized by removing the water molecules and undesired molecules, adding polar hydrogens and Gasteiger charges, and generating the $\mathrm{Zn}$ using zinc_pseudo.py.

\section{Three-dimensional structure of ligands}

The three-dimensional structure of ligands used in this study were: resveratrol, gnetol, isorhapontigenin, trans-piceid, gnetin C, trans- $\mathcal{E}$-viniferin, gnemonol $\mathrm{K}$, gnemonol $\mathrm{M}$, gnemonoside $\mathrm{A}$, gnemonoside $\mathrm{B}$, gnemonoside $\mathrm{C}$, gnemonoside $\mathrm{D}$, latifolol and aglycone of gnemonoside B. Lisinopril, captopril, and enalaprilat were also used as reference standards of free energy binding value and ligand-ACE interactions. All these ligands were obtained from http://www.pubchem.com. Charges were added to each ligand using AM1-BCC of Antechamber. Furthermore, all ligands were minimized using Sander to establish the relaxed structures. At last, all ligands were converted into pdbqt formats using python before performing the molecular docking.

\section{Methods}

Molecular docking was conducted using the AutoDock4Zn force field to generate the grid parameter files ( ${ }^{*}$.gpf) of ligand-ACE complexes. The grid center was set up with the grid center coordinate of $x=40.553$, $y=32.798$, and $z=47.286$. The grid box size used was configured into 40x40x40 Å with $0,375 \AA$ A spacing. The molecular docking was performed for 100 times (ga_run $=100$ ). Then, a scoring of free energy binding $(\Delta \mathrm{G})$ values of each ligand was performed based on the best energy and best cluster criteria. Furthermore, the visualization of ligand-ACE interactions was performed using LigandScout 4.09.2 and PoseView. The interactions of ligand-ACE complexes were analyzed based on pharmacophores which were compared with lisinopril, captopril, and enalaprilat. Meanwhile, the ligand-ACE interactions based on visualization using LigandScout (Figure 1) 4.09.2 and PoseView (Figure 2) indicated that each compound isolated from melinjo seeds was able to bind the active site of ACE via hydrogen bonds or hydrophobic interactions. Subsequently, based on Table 2 , several contents were able to bind $\mathrm{Zn}^{2+}$ ion via cation-pi interactions.

Molecular dynamics simulations were carried out at temperatures of $300 \mathrm{~K}$ and $310 \mathrm{~K}$ within $20 \mathrm{~ns}$ for each ligand-ACE complex. The simulation showed that resveratrol, gnetol, isorhapontigenin, trans-piceid, gnetin $\mathrm{C}$, trans- $\varepsilon$-viniferin, gnemonol $\mathrm{K}$, gnemonol $\mathrm{M}$, gnemonoside $\mathrm{C}$, and aglycone of gnemonoside $B$ exhibited the free energy binding $(\Delta G)$ lower and close to lisinopril, captopril, and enalaprilat. Gnemonoside D and trans-piceid were not selected since these ligands were the glucoside of gnetin $\mathrm{C}$ and resveratrol respectively that might be hydrolyzed by the hydrolase enzyme. The temperature of $300 \mathrm{~K}$ was chosen since it has been the default temperature of molecular dynamics simulations, while the temperature of $310 \mathrm{~K}$ was selected in an attempt to follow the heat of a healthy human body. Afterward, each ligand-ACE complex was analyzed on RMSD, RMSF, the hydrogen bond occupancy, free energy binding $(\Delta G)$ calculations using MM-GBSA and MM-PBSA methods and cation-pi interactions between ligand and $\mathrm{Zn}^{2+}$ ion.

\section{RESULTS}

The results of molecular docking method by using AutoDock4Zn (Table 1) showed that resveratrol, gnetol, isorhapontigenin, trans-piceid, gnetin C, trans- $\varepsilon$-viniferin, gnemonol $\mathrm{K}$, gnemonol $\mathrm{M}$, gnemonoside $\mathrm{C}$, and aglycone of gnemonoside B exhibited free energy binding $(\Delta \mathrm{G})$ values which were lower than or close to the $\Delta \mathrm{G}$ values of lisinopril, captopril, and enalaprilat. Meanwhile, the ligand-ACE interactions based on visualization using LigandScout (Figure 1) 4.09.2 and PoseView (Figure 2) indicated that each compound isolated from melinjo seeds was able to bind the active site of ACE via hydrogen bonds or hydrophobic interactions. Subsequently, based on Table 2, several compounds were able to bind $\mathrm{Zn}^{2+}$ ion via cation-pi interactions.

Molecular dynamics simulations at a temperature of $300 \mathrm{~K}$ (Figure 3) showed that all ligand-ACE complexes except resveratrol-ACE and trans- $\varepsilon$-viniferin-ACE complexes exhibited the similar pattern of RMSD fluctuation compared to lisinopril-ACE, captopril-ACE, and enalaprilat-ACE. Consequently, these ligands were able to maintain the conformational stability of ligand-ACE complexes to the same extent as lisinopril-ACE, captopril-ACE, and enalaprilat-ACE.

Table 1: The results of free energy binding $(\Delta G)$ calculations by using AutoDock4Zn.

\begin{tabular}{|c|c|c|}
\hline No. & Ligand & Free energy binding $/ \Delta \mathrm{G}(\mathrm{kcal} / \mathrm{mol})$ \\
\hline 1 & Resveratrol & -7.05 \\
\hline 2 & Gnetol & -7.04 \\
\hline 3 & Isorhapontigenin & -7.19 \\
\hline 4 & trans-Piceid & -8.11 \\
\hline 5 & Gnetin C & -8.51 \\
\hline 6 & trans- $\varepsilon$-Viniferin & -8.13 \\
\hline 7 & Gnemonol K & -11.07 \\
\hline 8 & Gnemonol M & -8.26 \\
\hline 9 & Gnemonoside A & -6.1 \\
\hline 10 & Gnemonoside B & -1.55 \\
\hline 11 & Gnemonoside C & -6.14 \\
\hline 12 & Gnemonoside D & -7.29 \\
\hline 13 & Latifolol & -6.19 \\
\hline 14 & $\begin{array}{c}\text { Aglycone of gnemonoside } \\
\text { B }\end{array}$ & -10.68 \\
\hline 15 & Lisinopril & -10.05 \\
\hline 16 & Captopril & -7.1 \\
\hline 17 & Enalaprilat & -9.98 \\
\hline
\end{tabular}



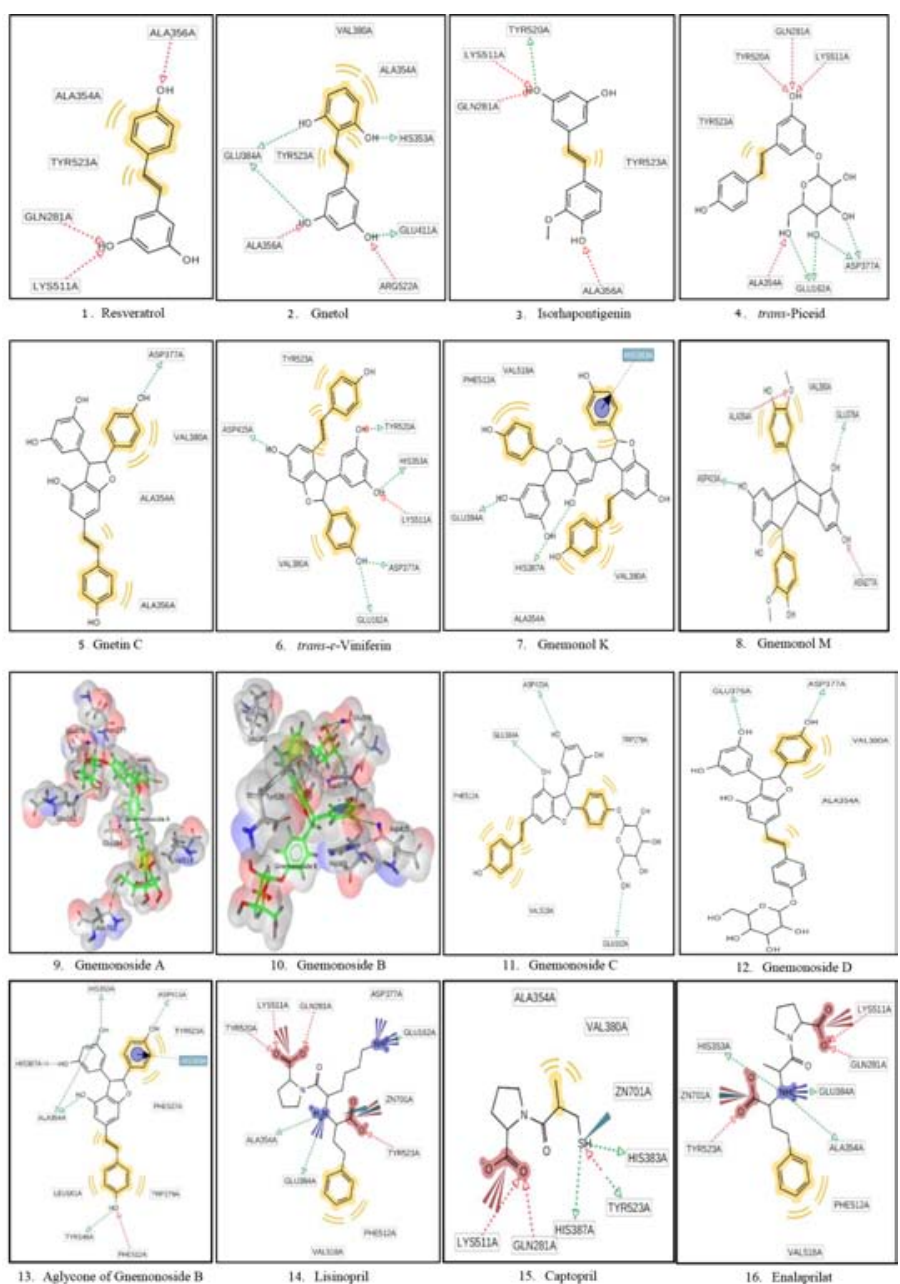

Figure 1: The visualization interactions of ligand-ACE complexes by using LigandScout 4.09.2.

The RMSF values of molecular dynamics simulations on both temperature of $300 \mathrm{~K}$ and $310 \mathrm{~K}$ (Figure 4) indicated that the temperature difference did not affect the RMSF value of each ligand-ACE complex.

As shown in Table 3, almost all ligands were able to form hydrogen bonds with amino acids in the active site of $\mathrm{ACE}$ whose occupancy values were higher than $25 \%$ within 20 ns of molecular dynamics simulations at temperatures of $300 \mathrm{~K}$ and $310 \mathrm{~K}$. Only resveratrol which did not exhibit the hydrogen bond occupancy greater or equal to $25 \%$ at a temperature of $300 \mathrm{~K}$ which demonstrated that the stability and the strength of resveratrol-ACE complex were poor.

Based on the MM-GBSA method at a temperature of $300 \mathrm{~K}$ shown in Table 4 , the lowest $\Delta \mathrm{G}$ value was exhibited by lisinopril indicating that there was no compound isolated from melinjo seeds which were able to match the affinity of lisinopril towards ACE. However, there were still ligands that had $\Delta \mathrm{G}$ values smaller than captopril and enalaprilat, such as gnetin $\mathrm{C}$, trans- $\varepsilon$-viniferin, gnemonol $\mathrm{K}$, and aglycone of gnemonoside B. Meanwhile, at a temperature of $310 \mathrm{~K}$, the smallest $\Delta \mathrm{G}$ was showed by the gnemonol $\mathrm{K}(-27.15 \mathrm{kcal} / \mathrm{mol})$.

Based on the calculation of $\Delta \mathrm{G}$ by MM-PBSA method at $300 \mathrm{~K}$ shown in Table 4, it can be concluded that lisinopril was the ligand with the smallest $\Delta G$ value. Moreover, in the calculation of $\Delta G$ with the MMPBSA method at a temperature of $310 \mathrm{~K}$, gnemonol $\mathrm{K}$ and the aglycone of gnemonoside $\mathrm{B}$ exhibited lower $\Delta \mathrm{G}$ value than lisinopril, captopril, and enalaprilat.
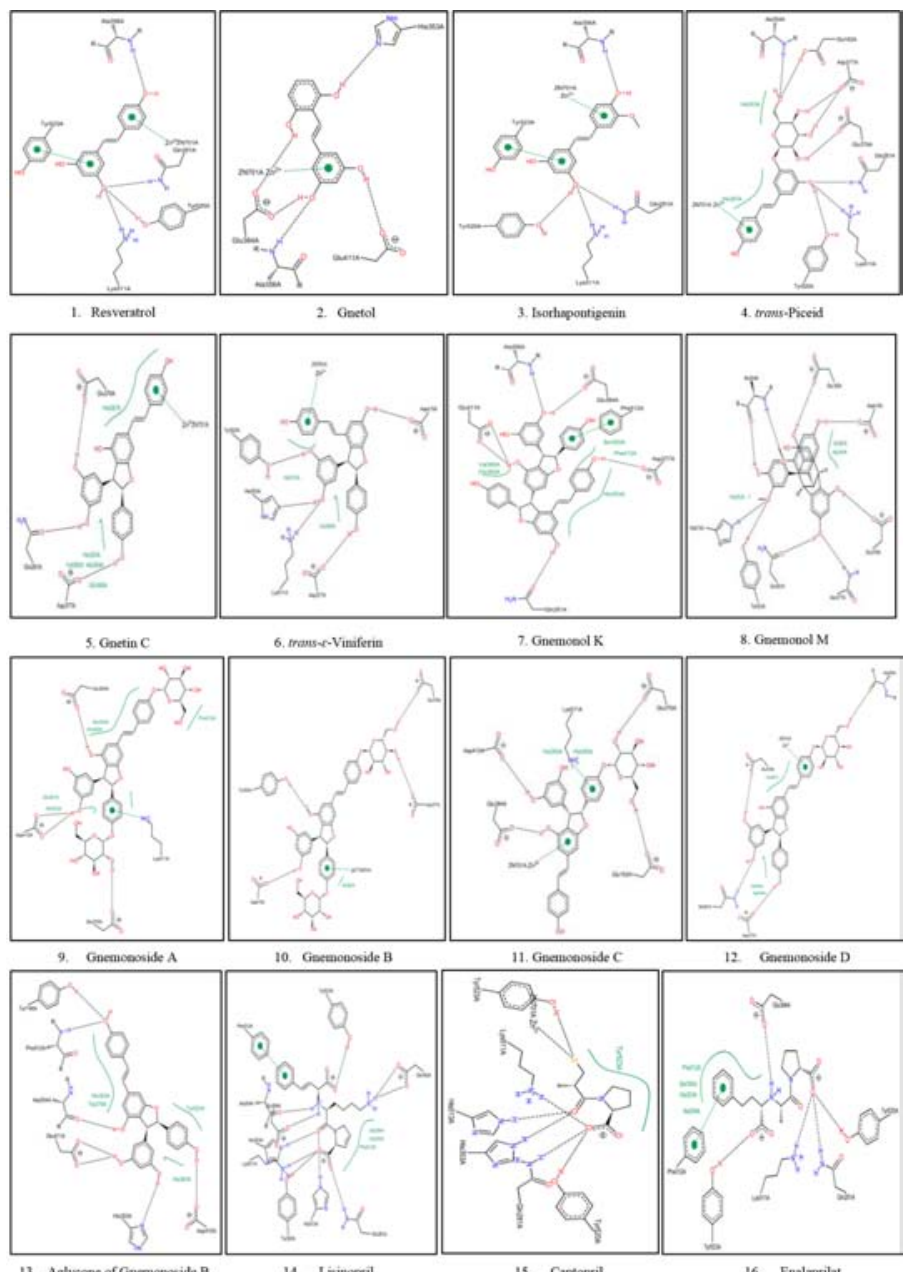

13. Allyecoe of Gnenomide B 14. Linegeil

15. Captopril

16. Enalegpilat

Figure 2: The visualization of ligand-ACE complexes interactions by using PoseView.

Based on Figure 5, all ligands except resveratrol were able to form relatively stable distance to the $\mathrm{Zn}^{2+}$ ion. Resveratrol exhibited a very fluctuating distance to the $\mathrm{Zn}^{2+}$ ion during molecular dynamics simulations within $20 \mathrm{~ns}$ at a temperature of $300 \mathrm{~K}$. Meanwhile, at a temperature of $310 \mathrm{~K}$, all ligands were able to form relatively stable distance to the $\mathrm{Zn}^{2+}$ ion, including resveratrol.

\section{DISCUSSION}

Molecular docking method using AutoDock4Zn demonstrated that resveratrol, gnetol, isorhapontigenin, trans-piceid, gnetin $\mathrm{C}$, trans- $\varepsilon$ viniferin, gnemonol $\mathrm{K}$, gnemonol $\mathrm{M}$, gnemonoside $\mathrm{C}$, and aglycone of gnemonoside $\mathrm{B}$ exhibited $\Delta \mathrm{G}$ values which were lower than or close to positive controls (Table 1$)$. The lower of free energy binding $(\Delta \mathrm{G})$ values, the better affinity of ligand towards its receptor. Ligands can inhibit ACE catalytic mechanism via ligand- $\mathrm{Zn}^{2+}$ ion or ligand-amino acids interactions in the active site of ACE. Interestingly, resveratrol, gnetol, isorhapontigenin, trans-piceid, gnetin $\mathrm{C}$, trans- $\varepsilon$-viniferin, gnemonoside $\mathrm{C}$ were able to bind the $\mathrm{Zn}^{2+}$ ion (Table 2). Therefore, based on the $\Delta \mathrm{G}$ and visualization interactions result, it suggested that resveratrol, gnetol, isorhapontigenin, trans-piceid, gnetin $\mathrm{C}$, trans- $\varepsilon$-viniferin, gnemonol $\mathrm{K}$, gnemonol $\mathrm{M}$, gnemonoside $\mathrm{C}$, and aglycone of gnemonoside $\mathrm{B}$ potentially have ACE inhibitory activity. 

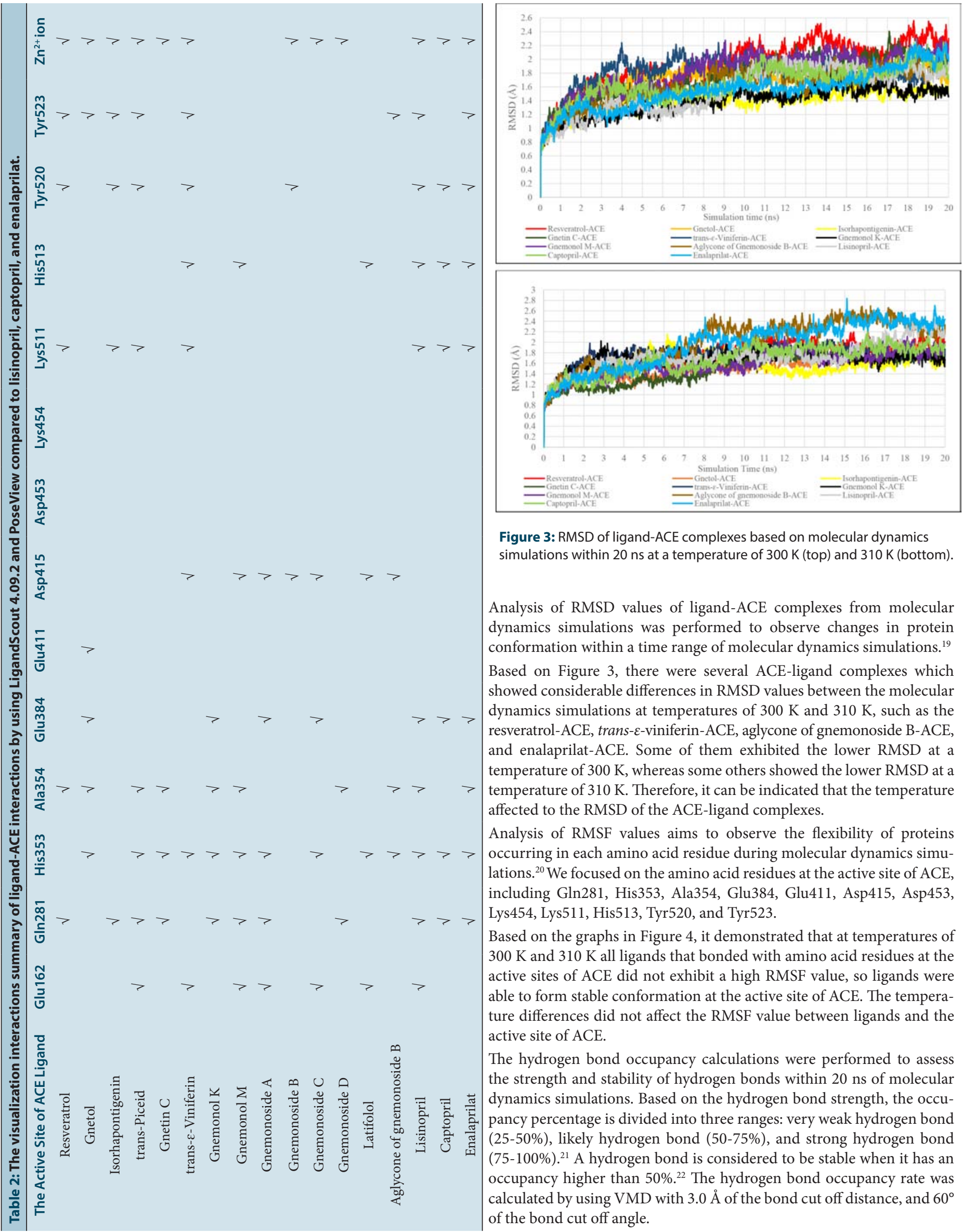

Figure 3: RMSD of ligand-ACE complexes based on molecular dynamics simulations within $20 \mathrm{~ns}$ at a temperature of $300 \mathrm{~K}$ (top) and $310 \mathrm{~K}$ (bottom).

Analysis of RMSD values of ligand-ACE complexes from molecular dynamics simulations was performed to observe changes in protein conformation within a time range of molecular dynamics simulations. ${ }^{19}$

Based on Figure 3, there were several ACE-ligand complexes which showed considerable differences in RMSD values between the molecular dynamics simulations at temperatures of $300 \mathrm{~K}$ and $310 \mathrm{~K}$, such as the resveratrol-ACE, trans- $\varepsilon$-viniferin-ACE, aglycone of gnemonoside B-ACE, and enalaprilat-ACE. Some of them exhibited the lower RMSD at a temperature of $300 \mathrm{~K}$, whereas some others showed the lower RMSD at a temperature of $310 \mathrm{~K}$. Therefore, it can be indicated that the temperature affected to the RMSD of the ACE-ligand complexes.

Analysis of RMSF values aims to observe the flexibility of proteins occurring in each amino acid residue during molecular dynamics simulations. ${ }^{20} \mathrm{We}$ focused on the amino acid residues at the active site of ACE, including Gln281, His353, Ala354, Glu384, Glu411, Asp415, Asp453, Lys454, Lys511, His513, Tyr520, and Tyr523.

Based on the graphs in Figure 4, it demonstrated that at temperatures of $300 \mathrm{~K}$ and $310 \mathrm{~K}$ all ligands that bonded with amino acid residues at the active sites of ACE did not exhibit a high RMSF value, so ligands were able to form stable conformation at the active site of ACE. The temperature differences did not affect the RMSF value between ligands and the active site of ACE.

The hydrogen bond occupancy calculations were performed to assess the strength and stability of hydrogen bonds within $20 \mathrm{~ns}$ of molecular dynamics simulations. Based on the hydrogen bond strength, the occupancy percentage is divided into three ranges: very weak hydrogen bond (25-50\%), likely hydrogen bond (50-75\%), and strong hydrogen bond (75-100\%). ${ }^{21} \mathrm{~A}$ hydrogen bond is considered to be stable when it has an occupancy higher than $50 \% .{ }^{22}$ The hydrogen bond occupancy rate was calculated by using VMD with $3.0 \AA$ of the bond cut off distance, and $60^{\circ}$ of the bond cut off angle. 
Table 3: The comparison of hydrogen bond occupancy of ligand-ACE complexes between the molecular dynamics simulations at temperatures of $300 \mathrm{~K}$ and $310 \mathrm{~K}$.

\begin{tabular}{|c|c|c|c|c|c|c|}
\hline Ligand & $\begin{array}{l}\text { Hydrogen Bond } \\
\text { Donor } 300 \mathrm{~K}\end{array}$ & $\begin{array}{l}\text { Hydrogen Bond } \\
\text { Acceptor } 300 \mathrm{~K}\end{array}$ & $\begin{array}{l}\text { Occupancy } \\
\text { (\%) } 300 \mathrm{~K}\end{array}$ & $\begin{array}{l}\text { Hydrogen Bond } \\
\text { Donor } 310 \mathrm{~K}\end{array}$ & $\begin{array}{l}\text { Hydrogen Bond } \\
\text { Acceptor } 310 \mathrm{~K}\end{array}$ & Occupancy (\%) $310 \mathrm{~K}$ \\
\hline Resveratrol & - & - & - & LIG580-Side-O1 & ALA315-Main-O & 29.40 \\
\hline \multirow[t]{6}{*}{ Gnetol } & LIG-Side-O3 & GLU411-Side-OE2 & 80.60 & LIG-Side-O2 & ALA354-Main-O & 97.30 \\
\hline & & & & LIG-Side-O3 & GLU411-Side-OE2 & 93.30 \\
\hline & & & & LIG-Side-O1 & GLU62-Side-OE2 & 72.10 \\
\hline & & & & TYR523-Side-OH & LIG-Side-O3 & 43.65 \\
\hline & & & & LIG-Main-O & GLU376-Side-OE2 & 43.35 \\
\hline & & & & LYS511-Side-NZ & LIG-Main-O & 29.95 \\
\hline \multirow[t]{2}{*}{ Isorhapontigenin } & LYS511-Side-NZ & LIG-Side-O3 & 33.40 & HIS513-Side-NE2 & LIG-Side-O2 & 32.95 \\
\hline & & & & LIG-Side-O3 & GLU384-Side-OE2 & 29.50 \\
\hline \multirow[t]{6}{*}{ Gnetin C } & LIG-Side-O3 & ASP377-Side-OD2 & 89.50 & LIG-Side-O3 & ASP377-Side-OD1 & 59.90 \\
\hline & ALA354-Main-N & LIG-Main-O & 26.90 & LIG-Side-O2 & HIS513-Side-ND1 & 51.80 \\
\hline & & & & ALA354-Main-N & LIG-Main-O & 48.55 \\
\hline & & & & LIG-Side-O3 & ASP377-Side-OD2 & 40.70 \\
\hline & & & & LIG-Side-O1 & GLU162-Side-OE2 & 34.15 \\
\hline & & & & TYR146-Side-OH & LIG-Side-O1 & 25.40 \\
\hline \multirow[t]{11}{*}{ 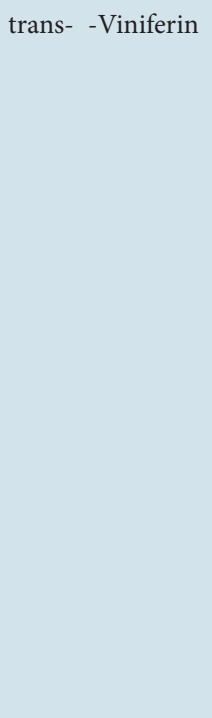 } & LIG-Main-O & ALA354-Main-O & 93.80 & LIG-Side-O5 & ASP377-Side-OD1 & 78.45 \\
\hline & LIG-Side-O4 & GLU162-Side-OE2 & 55.25 & LIG-Side-O1 & ASP453-Side-OD2 & 39.30 \\
\hline & LIG-Side-O1 & ASP453-Side-OD2 & 54.10 & LIG-Side-O1 & ASP453-Side-OD1 & 31.50 \\
\hline & LIG-Side-O4 & GLU162-Side-OE1 & 47.40 & LIG-Side-O4 & GLU162-Side-OE2 & 26.20 \\
\hline & LIG-Side-O1 & ASP453-Side-OD1 & 33.15 & & & \\
\hline & $\begin{array}{l}\text { THR166-Side- } \\
\text { OG1 }\end{array}$ & LIG-Side-O5 & 30.30 & & & \\
\hline & LYS511-Side-NZ & LIG-Side-O3 & 25.50 & & & \\
\hline & LIG-Side-O4 & GLU384-Side-OE1 & 49.05 & LIG-Side-O6 & GLU411-Side-OE2 & 74.90 \\
\hline & ALA356-Main-N & LIG-Side-O4 & 48.20 & LIG-Side-O4 & GLU384-Side-OE1 & 28.20 \\
\hline & $\begin{array}{l}\text { GLN281-Side- } \\
\text { NE2 }\end{array}$ & LIG-Side-O7 & 32.45 & LYS511-Side-NZ & LIG-Side-O7 & 28.15 \\
\hline & LIG-Side-O8 & GLU162-Side-OE1 & 27.60 & & & \\
\hline \multirow[t]{5}{*}{ Gnemonol M } & LIG-Side-O4 & ASP453-Side-OD2 & 81.10 & LIG-Side-O4 & ASP453-Side-OD2 & 86.50 \\
\hline & LIG-Side-O3 & ASP415-Side-OD1 & 62.55 & LIG-Side-O5 & ASP453-Main-O & 67.25 \\
\hline & LIG-Side-O5 & ASP453-Main-O & 47.85 & LIG-Side-O1 & ALA354-Main-O & 59.20 \\
\hline & LIG-Side-O5 & THR282-Side-OG1 & 34.55 & LIG-Side-O3 & ASP415-Side-OD1 & 48.00 \\
\hline & & & & LIG-Side-O2 & ASP415-Side-OD2 & 29.60 \\
\hline Gnemonol K & LIG-Side-O1 & ASP415-Side-OD1 & 95.95 & LIG-Side-O7 & CYS352-Main-O & 79.00 \\
\hline
\end{tabular}


Yanuar, et al.: Analysis of Compounds Isolated from Gnetum gnemon L. Seeds as Potential ACE Inhibitors

\begin{tabular}{|c|c|c|c|c|c|c|}
\hline \multirow[t]{5}{*}{$\begin{array}{l}\text { Aglycone of } \\
\text { gnemonoside B }\end{array}$} & LIG-Side-O4 & GLU384-Side-OE1 & 86.35 & LIG-Side-O5 & ALA354-Main-O & 98.00 \\
\hline & LIG-Side-O3 & GLN369-Side-OE1 & 80.95 & LIG-Side-O4 & GLU411-Side-OE2 & 87.05 \\
\hline & & & & LIG-Side-O2 & GLU162-Side-OE1 & 33.85 \\
\hline & & & & LIG-Side-O2 & GLU162-Side-OE2 & 31.55 \\
\hline & & & & LIG-Side-O3 & VAL380-Main-O & 25.90 \\
\hline \multirow[t]{4}{*}{ Lisinopril } & TYR523-Side-OH & LIG-Side-O1 & 56.40 & LIG-Side-O3 & GLU411-Side-OE2 & 98.65 \\
\hline & LIG-Side-O3 & ALA354-Main-O & 50.35 & TYR520-Side-OH & LIG-Side-O4 & 64.60 \\
\hline & HIS513-Side-NE2 & LIG-Side-O1 & 32.55 & HIS513-Side-NE2 & LIG-Side-O1 & 47.60 \\
\hline & LYS511-Side-NZ & LIG-Side-O4 & 28.75 & HIS353-Side-NE2 & LIG-Side-O1 & 27.05 \\
\hline \multirow[t]{2}{*}{ Captopril } & TYR520-Side-OH & LIG-Side-O2 & 61.65 & TYR520-Side-OH & LIG-Side-O2 & 34.70 \\
\hline & & & & LYS511-Side-NZ & LIG-Side-O2 & 32.45 \\
\hline \multirow[t]{2}{*}{ Enalaprilat } & LIG-Side-O2 & GLU411-Side-OE2 & 132.25 & LIG-Side-O2 & GLU411-Side-OE2 & 168.95 \\
\hline & TYR523-Side-OH & LIG-Side-O2 & 27.50 & HIS353-Side-NE2 & LIG-Side-N1 & 40.00 \\
\hline
\end{tabular}
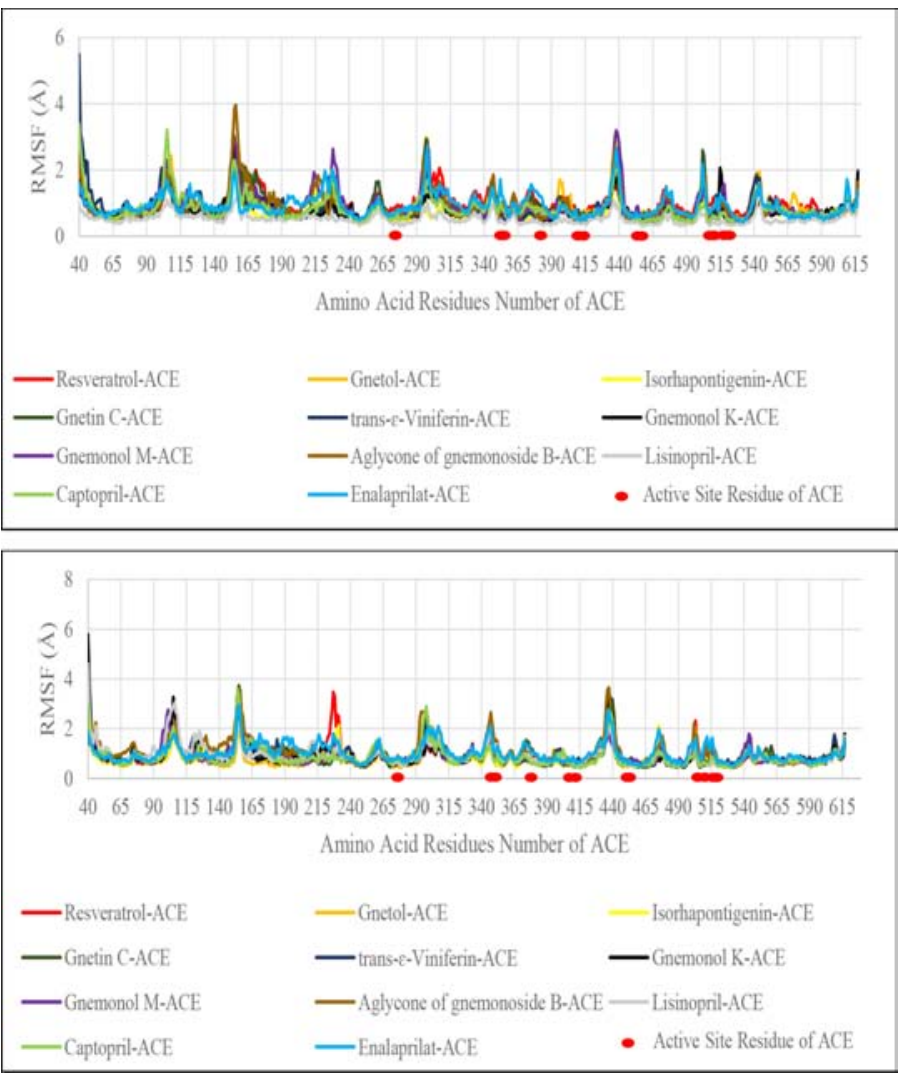

Figure 4: RMSF of ligand-ACE complexes based on molecular dynamics simulations within $20 \mathrm{~ns}$ at a temperature of $300 \mathrm{~K}$ (top) and $310 \mathrm{~K}$ down (bottom).

Based on Table 3, it can be considered that the hydrogen bond occupancy was likely to change by the $10 \mathrm{~K}$ temperature differences. Most ligands exhibited higher occupancy value towards amino acids residues in the active site of ACE at a temperature of $310 \mathrm{~K}$ rather than $300 \mathrm{~K}$. It can be concluded that the ACE inhibitory activities of these ligands were better at an average human body temperature. Otherwise, only gnemonol K-ACE and captopril-ACE complexes which had better occupancy at a temperature of $300 \mathrm{~K}$. The hydrogen bond occupancy between enalaprilat and Glu411 at temperatures of $300 \mathrm{~K}$ and $310 \mathrm{~K}$ were higher than $100 \%$, which indicated that there were two hydrogen bonds occurred between them at the same time.

MM-GBSA and MM-PBSA methods were capable of calculating the free energy binding $(\Delta G)$ of a ligand towards a macromolecule, either in a solvated state or a vacuum. Based on Table 4, both MM-GBSA and MM-PBSA methods exhibited different free energy binding $(\Delta G)$. Also, the $10 \mathrm{~K}$ temperature differences led the significant changes in free energy binding $(\Delta G)$ of some ligands both in the MM-GBSA and MM-PBSA methods. Both methods were able to generate more accurate free energy binding $(\Delta \mathrm{G})$ values than docking and scoring methods. ${ }^{23}$

Fluctuations in interaction distance of aromatic ring in ligands with $\mathrm{Zn}^{2+}$ ion were observed to assess the stability of the cation-pi interactions that occurred during the simulation of $20 \mathrm{~ns}$ molecular dynamics, both at 300 $\mathrm{K}$ and $310 \mathrm{~K}$. Then, visualization process was carried out at the closest distance between aromatic ring of ligands with $\mathrm{Zn}^{2+}$ by using LigandScout 4.09.2 to identify the presence of cation-pi interactions. A cation-pi interaction can occur within a distance of $6.0 \AA \AA^{24}$

Based on the graph in Figure 5, resveratrol showed a very fluctuating distance to $\mathrm{Zn}^{2+}$ ion after passing a three ns simulation time which indicated that the cation-phi bond between aromatic ring in resveratrol to $\mathrm{Zn}^{2+}$ ion only lasted for a short time. Meanwhile, aromatic rings in other ligands were stable at a distance range of 4-7 A. Based on the visualization process results by using LigandScout 4.09 .2 at the closest distance of aromatic ring of each ligand to $\mathrm{Zn}^{2+}$ ion, resveratrol, gnetol, isorhapontigenin, gnetin $\mathrm{C}$, gnemonol $\mathrm{K}$, and aglycone of gnemonoside $\mathrm{B}$ were able to form cation-pi interactions with the $\mathrm{Zn}^{2+}$ ion at a temperature of $300 \mathrm{~K}$. However, the aromatic ring of resveratrol showed a closer distance with $\mathrm{Zn}^{2+}$ at a temperature of $310 \mathrm{~K}$ compared to $300 \mathrm{~K}$. Meanwhile, the other ligands did not show significant differences in fluctuation of the aromatic ring distance to $\mathrm{Zn}^{2+}$ ion compared to the $300 \mathrm{~K}$ molecular dynamics simulations. Visualization process by using LigandScout 4.09 .2 at the aromatic rings of each ligand to $\mathrm{Zn}^{2+}$ at the closest distance between them, indicated that resveratrol, isorhapontigenin, gnetin $\mathrm{C}$, gnemonol $\mathrm{K}$, gnemonol $\mathrm{M}$, and aglycone gnemonoside $\mathrm{B}$ were able to form cation-phi interactions at $310 \mathrm{~K}$.

It is necessary to conduct the molecular docking and molecular dynamics analysis of other substances contained in melinjo seed extracts that have not been carried out in this study. Subsequently, it is needed to lengthen the simulation times of molecular dynamics to see further about ligand-ACE conformational changes. Preclinical and clinical tests are also required 

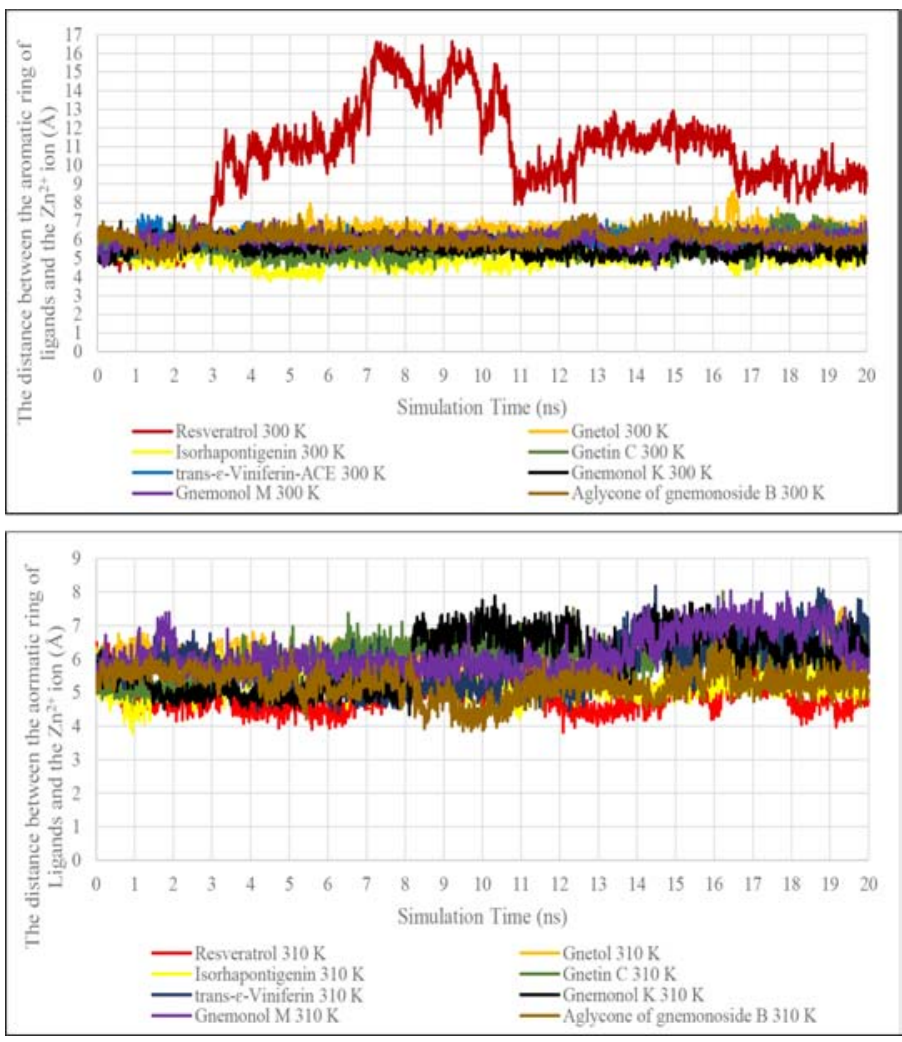

Figure 5: The distances between the aromatic ring of ligands with $\mathrm{Zn}^{2+}$ ion within $20 \mathrm{~ns}$ of molecular dynamics simulations at a temperature of $300 \mathrm{~K}$ (top) and $310 \mathrm{~K}$ (down).

Table 4: Free energy binding $(\Delta G)$ values of ligands to ACE based on calculations by using MM-GBSA, MM-PBSA, and AutoDock4Zn forcefield.

\begin{tabular}{cccccc}
\hline & \multicolumn{5}{c}{$\Delta$ G (kcal/mol) } \\
\cline { 2 - 5 } Ligand & \multicolumn{2}{c}{ MM-GBSA } & \multicolumn{2}{c}{ MM-PBSA } & AutoDock \\
\cline { 2 - 5 } & $300 \mathrm{~K}$ & $310 \mathrm{~K}$ & $300 \mathrm{~K}$ & $310 \mathrm{~K}$ & $4 \mathrm{Zn}$ \\
\hline Resveratrol & -6.49 & -8.64 & -3.34 & -5.15 & -7.05 \\
Gnetol & -17.08 & -14.27 & -11.62 & -13.49 & -7.04 \\
Isorhapontigenin & -15.14 & -13.29 & -4.00 & -6.04 & -7.19 \\
Gnetin C & -30.43 & -26.87 & -20.83 & -14.06 & -8.51 \\
trans-E-Viniferin & -23.08 & -12.12 & -14.59 & -7.14 & -8.13 \\
Gnemonol K & -25.60 & -27.15 & -13.64 & -18.02 & -11.07 \\
Gnemonol M & -18.94 & -23.27 & -6.26 & 0.00 & -8.26 \\
Aglycone of & & & & & \\
gnemonoside B & -28.11 & -22.83 & -18.53 & -16.90 & -10.68 \\
Lisinopril & -34.62 & -18.25 & -25.22 & -11.39 & -10.15 \\
Captopril & -14.46 & -19.40 & -9.86 & -14.89 & -7.1 \\
Enalaprilat & -22.63 & -17.12 & -12.23 & -16.36 & -9.98 \\
\hline
\end{tabular}

to perform for proving the ACE inhibitory activity of each substance. Furthermore, toxicity testing of each compound in melinjo seed extract is needed to evaluate the safety of each material when itis consumed.

\section{CONCLUSION}

Based on the in silico study through molecular docking and molecular dynamics simulations of several compounds isolated from Gnetum

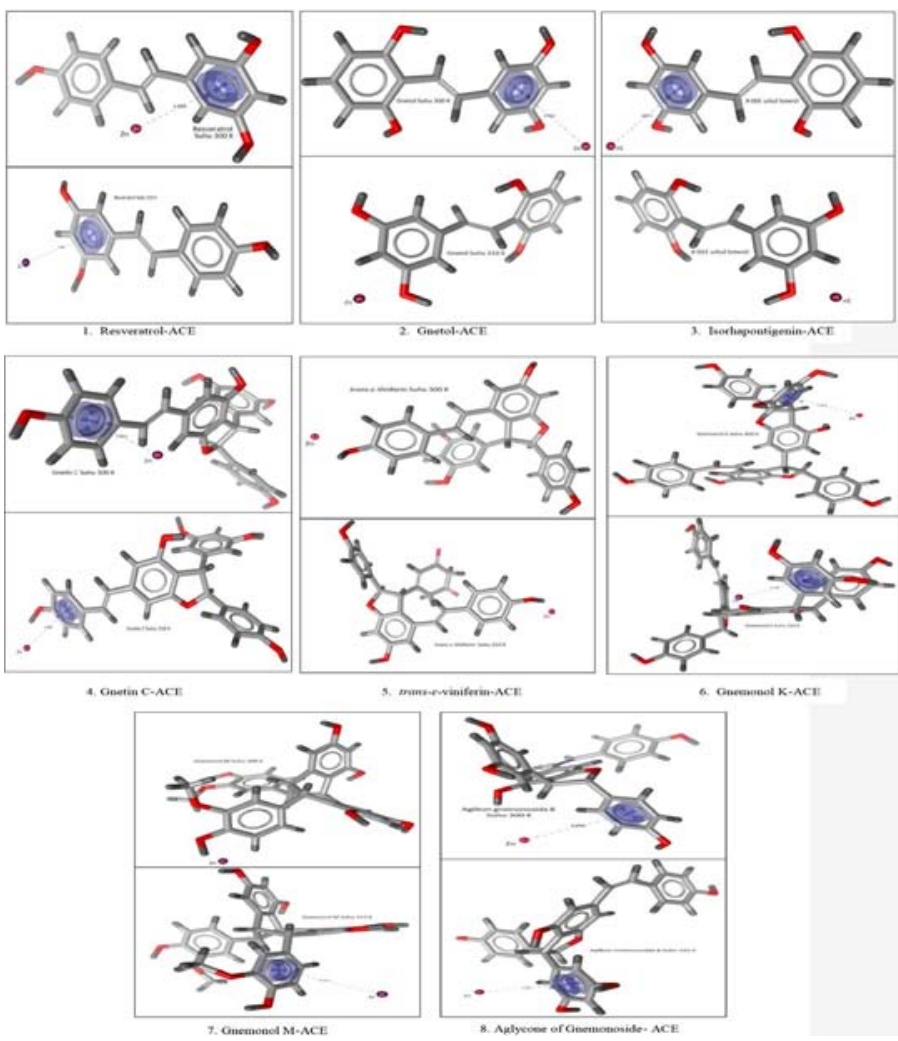

Figure 6: The 3D visualization of cation-pi interactions of ligand-ACE complexes at temperatures of $300 \mathrm{~K}$ (top) and $310 \mathrm{~K}$ (bottom) using LigandScout 4.09.

gnemon L., it may be concluded that resveratrol, gnetol, isorhapontigenin, gnetin $\mathrm{C}$, trans- $\varepsilon$-viniferin, gnemonol $\mathrm{K}$, gnemonol $\mathrm{M}$, and aglycone of gnemonoside $\mathrm{B}$ potentially have ACE inhibitory activity due to their free energy binding $(\Delta G)$, RMSD, RMSF, and the hydrogen bond occupancy compared to lisinopril, captopril, and enalaprilat. It was convinced by the visualization process by using LigandScout 4.09.2 and PoseView on each ligand-ACE complex which showed the binding pattern similarities between the compounds and positive controls, including lisinopril, captopril, and enalaprilat.

\section{ACKNOWLEDGEMENT}

The authors thank to Publikasi Internasional Terindeks Untuk Tugas Akhir Mahasiswa (PITTA) 2017 provided by the Directorate of Research and Community Engagement, Universitas Indonesia for the financial support to this study.

\section{CONFLICT OF INTEREST}

The authors declare no conflict of interest.

\section{ABBREVIATIONS}

ACE: Angiotensin Converting Enzyme; MM-GBSA: Molecular Mechanics Generelized Born Surface Area; MM-PBSA: Molecular Mechanics Poisson-Boltzmann Surface Area; PMEMD: Patial Mesh Ewal Molecular Dynamics; VMD: Visual Molecular Dynamics; RMSD: Root Mean Square Deviation; RMSF: Root Mean Square Fluctuation. 


\section{REFERENCES}

1. Narayanan NK, et al. Antitumor activity of melinjo (Gnetum gnemon L.) seed extract in human and murine tumor models in vitro and in a colon-26 tumorbearing mouse model in vivo. Cancer Med. 2015;4(11):1767-80.

2. Puspitaningrum YT, Efendi E, Siswoyo TA. Analisis in vivo aktivitas antihipertensi dari protein biji melinjo (Gnetum gnemon) terhidrolisis. Artikel IImiah Hasil Penelitian Mahasiswa. 2014;2(2):327-31.

3. Wells BG, DiPiro JT, Schwinghammer TL, DiPiro CV. Pharmacotherapy Handbook (9th ed.). New York: McGraw-Hill. 2015.

4. World Health Organization. World health statistics. 2012. March 15, 2017. http:// www.who.int/gho/publications/world_health_statistics/EN_WHS2012_Full.pdf

5. Lestari P, Katrin, Rissyelly, Maya PG. Inhibition Activity of Angiotensin Converting Enzyme (ACE) and Determination of Total Phenolic and Flavonoid Compound from Bitter Melon Leaves (Momordica charantia L.). Pharmacogn J. 2017;9(2):252-6

6. Badan Penelitian dan Pengembangan Kementerian Kesehatan RI. Riset Kesehatan Dasar Tahun 2013. Jakarta: Riskesdas. 2013.

7. Sweileh WM, Sawalha AF, Zyoud SH, Al-Jabil SW, Tameem EJ, Shraim NY. Evaluation of antihypertensive therapy in diabetic hypertensive patients: Impact of ischemic heart disease. J Pharm Pract. 2013:7(1):40-6.

8. Tutor JT, Chichioco-Hernandez CL. Angiotensin-Converting Enzyme Inhibition of Fractions from Eleusine indica Leaf Extracts. Pharmacogn J. 2018:10(1): 25-8.

9. Manner HI, Elevitch CR. Traditional trees of Pacific Island: Their culture, environment, and use. Hawaii: Permanent Agriculture Resources. 2006.

10. Huang KS, Li RL, Wang YH, Lin M. Three new stilbene trimers from the lianas of Gnetum hainanense. Planta Medica. 2001;67:61-4.

11. Huang KS, Wang YH, Li RL, Lin M. Five new stilbene dimers from the lianas of Gnetum hainanense. Journal of National Product. 2000;63(1):86-9.

12. Huang KS, Wang YH, Li RL, Lin M. Stilbene dimers from the lianas of Gnetum hainanense. Phytochemistry. 2000;63(1):86-9.

13. Hafidz KA, et al. HMG-CoA Reductase Inhibitory Activity of Gnetum gnemon Seed Extract and Identification of Potential Inhibitors for Lowering Cholesterol Level. J Young Pharm. 2017;9(4):559-65.

14. Munadhil MA. Uji aktivitas penghambatan angiotensin converting enzyme (ACE) dan penetapan kadar fenolik total dari biji melinjo (Gnetum gnemon L.).
Depok: Fakultas Farmasi Universitas Indonesia. 2016.

15. Mun'im A, Munadhil MA, Puspitasari N, Azminah, Yanuar A. Angiotensinconverting enzyme inhibitory activity of melinjo (Gnetum gnemon L.) Seed extracts and molecular docking of its stilbene constituents. Asian J Pharm Clin Res. 2017;10(3):243-8.

16. Shukor NA, et al. Angiotensin-converting enzyme inhibitory effects by plant phenolic 2 compounds: A study of structure-activity relationships. J Agric Food Chem. 2013:61(48):11832-9.

17. Santos-Martins D, Forli S, Ramos MJ, Olson AJ. AutoDock4Zn: An improved AutoDock force field for small-molecule docking to zinc metalloproteins. J Chem Inf Model. 2014;54(8):2371-9.

18. Priya $R$, et al. Molecular docking and molecular dynamics to identify a novel human immunodeficiency virus inhibitor from alkaloids of Toddalia asiatica. Pharmacogn Mag. 2015;11(4):414-22.

19. Salsbury FR. Molecular dynamics simulations of protein dynamics and their relevance to drug discovery. Curr Opin Pharmacol. 2010;10(6):738-44.

20. Fraccalvieri $\mathrm{D}$, et al. Conformational and functional analysis of molecular dynamics trajectories by self-organising maps. BMC Bioinformatics. 2011;12(1):158.

21. Kästner J, Loeffler HH, Roberts SK, Fernandez MI, Winn MD. Ectodomain orientation, conformational plasticity and oligomerization of erbB1 receptors investigates by molecular dynamics. J Struct Biol. 2009;167(2):117-28.

22. Desheng L, Jian G, Yuanhua C, Wei C, Huai Z, Mingjuan J. Molecular dynamics simulations and MMP/GBSA methods to investigate binding mechanism of aminomethylpyrimidine inhibitor with DPP-IV. Bioorg Med Chem Lett. $2011 ; 21(22): 6630-5$.

23. Genheden S, Ryde U. The MM/PBSA and MM/GBSA methods to estimate ligand-binding affinities. Expert Opin Drug Discov. 2015;10(5):449-61.

24. Gallivan JP, Dougherty DA. Cation-pi interactions in structural biology. Proc Natl Acad Sci USA. 1999;96(17):9459-64.

Article History: Submission Date : 29-11-2017 ; Revised Date : 28-01-2018; Acceptance Date : 12-04-2018.

Cite this article: Triputra MA, Yanuar A. Analysis of Compounds Isolated from Gnetum gnemon L. Seeds as Potential ACE Inhibitors through Molecular Docking and Molecular Dynamics Simulations. JYoung Pharm. 2018;10(2)Suppl:s32-s39. 